\title{
SLOPE FAILURE RISK ASSESSMENT MODELING USING TOPOGRAPHIC DATA AND NUMERICAL CALCULATION OF SOIL CONSERVATION BY TREE ROOT SYSTEMS
}

\author{
Taiki Mori ${ }^{1}$, Tomoyasu Sugiyama ${ }^{2}$, Ikuya Hosooka ${ }^{1}$, Makoto Nakata ${ }^{3}$, Kazuyuki Okano ${ }^{4}$, Yoshifumi Satofuka ${ }^{5}$
}

\begin{abstract}
1 Structural Engineering Office, West Japan Railway Company, Osaka, Japan, (taiki-mori, ikuya-hosooka) @westjr.co.jp
2 Graduate School of Engineering, Kyoto University, Kyoto, Japan, sugiyama.tomoyasu.4n@kyoto-u.ac.jp

3 National Land Conservation Technical Dept, Asia Air Survey CO., LTD, Kanagawa, Japan, mak.nakata@ajiko.co.jp 4 Nishi-Nihon National Land Conservation Consulting Dept, Asia Air Survey CO., LTD, Osaka, Japan, kaz.okano@ajiko.co.jp 5 College of Scienc and Engineering, Ritsumeikan University, Shiga, Japan, satofuka@se.ritsumei.ac.jp
\end{abstract}

\section{Commission IWIDF}

KEY WORDS: Digital Topographic Data, Slope Failure Risk Assessment, Soil Conservation, Topsoil Thickness, Tree Root System, Railway

\begin{abstract}
:
In Japan, the frequency of sudden heavy rain events has recently increased, causing slope failures that in turn increase rates of damage to transit infrastructure such as railways and roads. To reduce this damage, there is a need to identify locations near railroad tracks that are at risk of slope failure. Thus, an assessment that predicts whether or not damage will occur due to external forces such as heavy rains is required, rather than a simple relative risk assessment based on identifying locations similar to those damaged in previous events. In this study, we developed a method for time series stability assessment of slopes during heavy rains using digital topographic data. This method uses topographic data to estimate topsoil thickness, which contributes to stability, and soil strength, which is affected by the root systems of vegetation on slopes. Using differences in these parameters between tree species and forest type, we were able to calculate slope stability and simulate slope failure during rainfall. The simulations allowed us to evaluate locations along routes where previous failures occurred, and to identify at-risk locations that have not yet experienced slope failure. This approach will improve forest management based on risk assessments for intensifying heavy rains.
\end{abstract}

\section{INTRODUCTION}

In Japan, the frequency of sudden heavy rain events has recently increased, causing slope failures that in turn increase rates of damage to transit infrastructure such as railways and roads. To reduce this damage, there is a need to identify locations near railroad tracks that are at risk of slope failure. To this end, the railroad administrators currently identify characteristics of slope failure sites from past disaster data and identify locations found to be similar in nature from field surveys as being hazardous places. This work, however, needs considerable labor and can only be carried out in limited areas. The characteristics of slope failure sites vary depending on the local topography or geology. Where no slope failure disasters occurred in the past, it is difficult to learn the characteristics of a location with a high risk of slope failure. Assessment of slope risk over a wide area requires an assessment method that is highly applicable to various locations and needs less labor.

There is research on the prediction of slope stability using an analytical method based on physical laws. Okimura et al. (1985) proposed a technique that assesses slope risk over a wide area by infinite slope stability analysis using numerical topographic model. Asano et al. (2013) approximated the groundwater level and saturation percentage in the soil using a simple equation based on the numerical experiment to consider the unsaturated infiltration process in the soil and proposed a revised version of the assessment technique of Okimura et al. (1985).

In these assessment techniques, the topsoil layer thickness greatly affects stability of the slope. It is pointed out that the preparation of a spatial model of topsoil layer thickness requires a great amount of effort. Mountain slope surfaces in Japan are generally covered by vegetation. These techniques consider the effect of the vegetation on slope stability in the form of adhesion of the root system. However, no techniques of spatial modeling of adhesion are proposed.

In this research, the binding power of the root system, which differs depending on the thickness of the topsoil layer or the vegetation on a slope, are modeled based on aerial laser measurement data, and a technique that assesses the risk of a slope using these models is proposed.

\section{CALCULATION METHOD}

\subsection{Summary and aim}

We estimated topsoil thickness and soil-related vegetation characteristics based on aerial photographs and digital topographic data. Using these data as input, we modified the slope stability calculation method (Nunokawa et al., 2013) to increase its precision for use in vegetation management and future environmental assessments on slopes near railroad tracks. The characteristics of the revised calculation model are as follows.

\footnotetext{
- Assessments account for external forces due to intensified heavy rains.

- Extraction of newly identified at-risk locations as well as those previously damaged.
} 
- Disaster-resistance simulations based on current or different vegetation species.

- Assessment of areas from disaster prevention and ecology (environmental) perspectives, and application to forest management.

In this study, we present a method to calculate soil strength based on estimated topsoil thickness and data describing vegetation root systems, and the results of trial calculations using these methods.

\subsection{Data collection from test sites}

The study site was a watershed with a depth of $300 \mathrm{~m}$ along the Japan Railway, at which five surface failures occurred due to heavy rains in August 2014 in Northern Kyoto (Figure 1). Aerial photographs and aerial laser measurements were taken at these locations. Vegetation in the watershed was classified, and $50-\mathrm{cm}$ digital three-dimensional (3D) topographic data were obtained by interpretation of photographs and laser measurements. Topsoil strength parameters and thickness were determined using field surveys via simple dynamic cone penetration tests. Physical characteristics of the soil, such as strength and water permeability, were determined from soil samples.

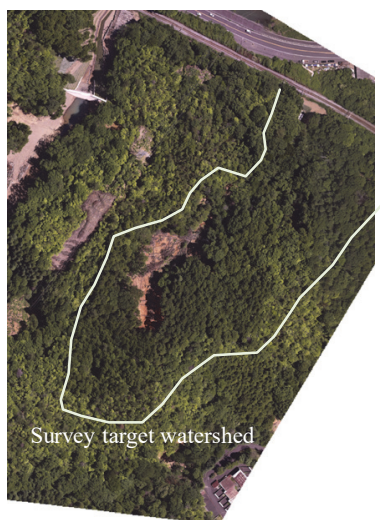

(1) Aerial photograph

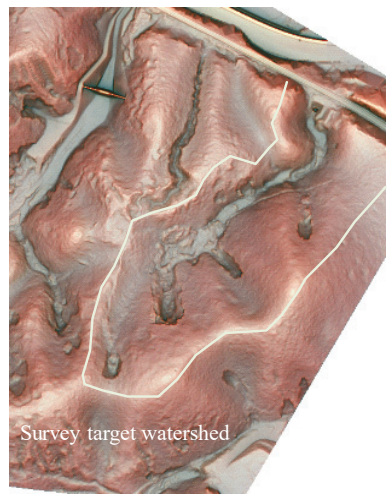

(2) 3D representation based on three-dimensional topographic data

Figure 1. (1) Aerial photograph and (2) topography of the target watershed

\section{TOPSOIL THICKNESS ESTIMATION USING DIGITAL TOPOGRAPHIC DATA}

Simple cone penetration tests were conducted in the field to represent the entire watershed. Statistical analyses (type I quantification) were performed using the topsoil thickness at cone penetration test sites as the objective variable, and various types of topographic data obtained from laser measurements were the explanatory variables. As the correlation between slope incline and topsoil thickness differed around a slope incline threshold of $30^{\circ}$, locations were classified into those with slope inclines $<30^{\circ}$ and $\geq 30^{\circ}$. Different types of topographic data were used as explanatory variables: slope incline, catchment area, aboveground opening, and geological structure (dip or anti-dip slope). Slope incline, catchment area, and aboveground opening were easily determined from digital topographic data, and geological structure was obtained from a geologic map, without the need for field surveys. The analysis results are shown in Table 1. Figure 2 shows the relationships between experimental topsoil thickness and values estimated using the equations provided in Table 1, for arbitrary points along a 2-m mesh throughout the watershed. The distribution of estimated topsoil thickness generally conformed to the distribution of experimental values; thus, our results were sufficiently precise to estimate topsoil thickness without the need for additional field surveys. The correlation coefficient was 0.9 for slopes with $\mathrm{a}<30^{\circ}$ incline, and 0.7 for slopes $\geq 30^{\circ}$.

\begin{tabular}{|c|l|c|}
\hline \multicolumn{3}{|c|}{ Slope incline $<30^{\circ}$} \\
\hline \multirow{4}{*}{ Slope incline } & under $20^{\circ}$ & -0.07710 \\
\cline { 2 - 3 } & $20^{\circ} \sim 25^{\circ}$ & 0.21506 \\
\cline { 2 - 3 } & $25^{\circ} \sim 30^{\circ}$ & -0.04240 \\
\hline \multirow{5}{*}{$\begin{array}{l}\text { Catchment area } \\
\text { under } 10 \mathrm{~m}^{2}\end{array}$} & -0.29150 \\
\cline { 2 - 3 } & $10 \mathrm{~m}^{2} \sim 20 \mathrm{~m}^{2}$ & -0.18260 \\
\cline { 2 - 3 } & $20 \mathrm{~m}^{2} \sim 30 \mathrm{~m}^{2}$ & 0.06952 \\
\cline { 2 - 3 } & $30 \mathrm{~m}^{2} \sim 40 \mathrm{~m}^{2}$ & 0.18164 \\
\cline { 2 - 3 } $\begin{array}{c}\text { Aboveground } \\
\text { opening }\end{array}$ & $40 \mathrm{~m}^{2} \sim 50 \mathrm{~m}^{2}$ & 0.06068 \\
\cline { 2 - 3 } & $50 \mathrm{~m}^{2}$ or over & 0.23939 \\
\hline \multirow{5}{*}{ under $85^{\circ}$} & 0.47919 \\
\cline { 2 - 3 } & $85^{\circ} \sim 86^{\circ}$ & 0.24751 \\
\cline { 2 - 3 } & $86^{\circ} \sim 87^{\circ}$ & 0.69349 \\
\cline { 2 - 3 } & $87^{\circ} \sim 88^{\circ}$ & -0.46920 \\
\cline { 2 - 3 } & $88^{\circ} \sim 89^{\circ}$ & 0.21882 \\
\cline { 2 - 3 } & $89^{\circ}$ or over & -0.49880 \\
\hline \multirow{4}{*}{ Geological structure } & dip slope & -0.08060 \\
\cline { 2 - 3 } & anti-dip slope & 0.06046 \\
\hline Constant term & 1.44608 \\
\hline
\end{tabular}

(1) Slope incline $<30^{\circ}$

\begin{tabular}{|c|l|l|}
\hline \multicolumn{3}{|c|}{ Slope incline ? $30^{\circ}$} \\
\hline \multirow{4}{*}{ Slope incline } & $30^{\circ} \sim 35^{\circ}$ & 0.12626 \\
\cline { 2 - 3 } Catchment area & $35^{\circ}$ or over & -0.19510 \\
\hline \multirow{5}{*}{ Aboveground } & under $10 \mathrm{~m}^{2}$ & 0.04806 \\
\cline { 2 - 3 } opening & $10 \mathrm{~m}^{2} \sim 20 \mathrm{~m}^{2}$ & -0.14690 \\
\cline { 2 - 3 } & $20 \mathrm{~m}^{2} \sim 30 \mathrm{~m}^{2}$ & 0.08046 \\
\cline { 2 - 3 } & $30 \mathrm{~m}^{2} \sim 40 \mathrm{~m}^{2}$ & 0.08388 \\
\cline { 2 - 3 } & $40 \mathrm{~m}^{2} \sim 50 \mathrm{~m}^{2}$ & -0.16290 \\
\cline { 2 - 3 } & $50 \mathrm{~m}^{2}$ or over & -0.04740 \\
\hline \multirow{5}{*}{ under $85^{\circ}$} & 0.03754 \\
\cline { 2 - 3 } & $85^{\circ} \sim 86^{\circ}$ & -0.27130 \\
\cline { 2 - 3 } & $86^{\circ} \sim 87^{\circ}$ & 0.30878 \\
\cline { 2 - 3 } & $87^{\circ} \sim 88^{\circ}$ & 0.52812 \\
\cline { 2 - 3 } & $88^{\circ} \sim 89^{\circ}$ & -0.21900 \\
\cline { 2 - 3 } & $89^{\circ}$ or over & 0.07608 \\
\hline \multirow{4}{*}{ Geological structure } & dip slope & -0.01020 \\
\cline { 2 - 3 } & anti-dip slope & 0.00663 \\
\hline \multicolumn{2}{|c|}{ Constant term } & 1.12888 \\
\hline
\end{tabular}

(2) Slope incline $\geq 30^{\circ}$

Table 1. Topsoil thickness equation parameters determined by type I quantification statistical analysis 


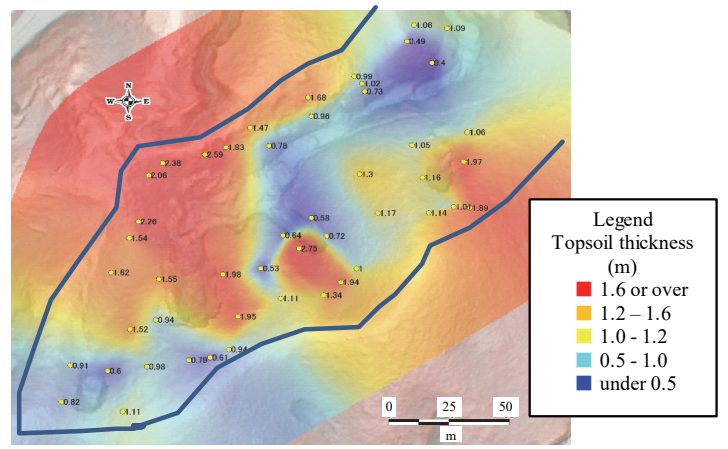

(1) Experimental values

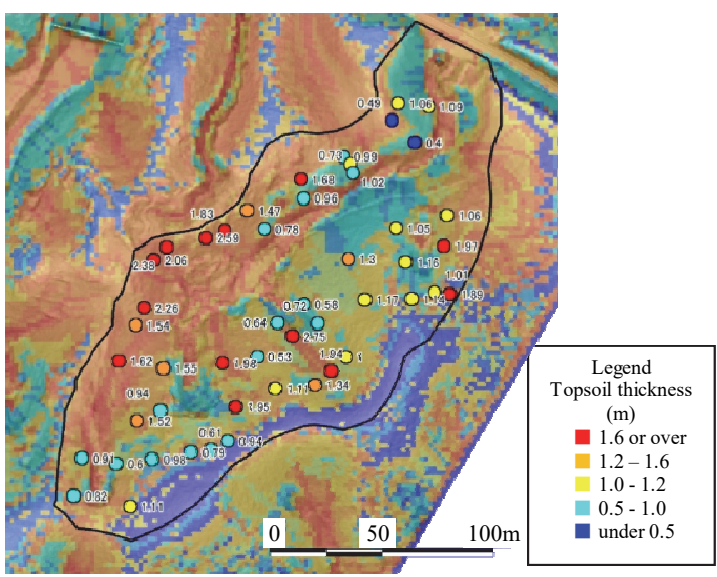

(2) Estimated values

Figure2. Distribution of slope topsoil thickness (m) values obtained from (1) simple field cone penetration measurements and (2) model predictions

\section{SOIL STRENGTH PARAMETERS BASED ON SLOPE ROOT SYSTEM EFFECTS ON SOIL CONSERVATION}

Generally, vegetation root systems increase the shear strength of soil, as shown by the following equation:

$$
\tau=\sigma \tan \phi+(c+\Delta c)
$$

where $\tau$ is the soil shear strength, $\varphi$ is the soil friction angle, $\mathrm{c}$ is the soil viscosity, and $\Delta \mathrm{c}$ is the increase in soil viscosity due to vegetation (mainly trees in the study site), which can be determined by the following equations (Atsuji, 2013, 2014):

Conifers (Japanese cypress): $\Delta c=\left(0.0033 D^{2.77}\right) X^{-2.8}$

Broadleaf trees: $\Delta c=0.00198(D / X)^{2.8}$

where $D$ is the tree diameter at breast height $(\mathrm{cm})$ and $X$ is the distance between trees $(\mathrm{m})$. Thus, tree species and diameter, and the inter-tree distance, can be used to determine the increase in soil viscosity due to the presence of trees (Figure 3 ).

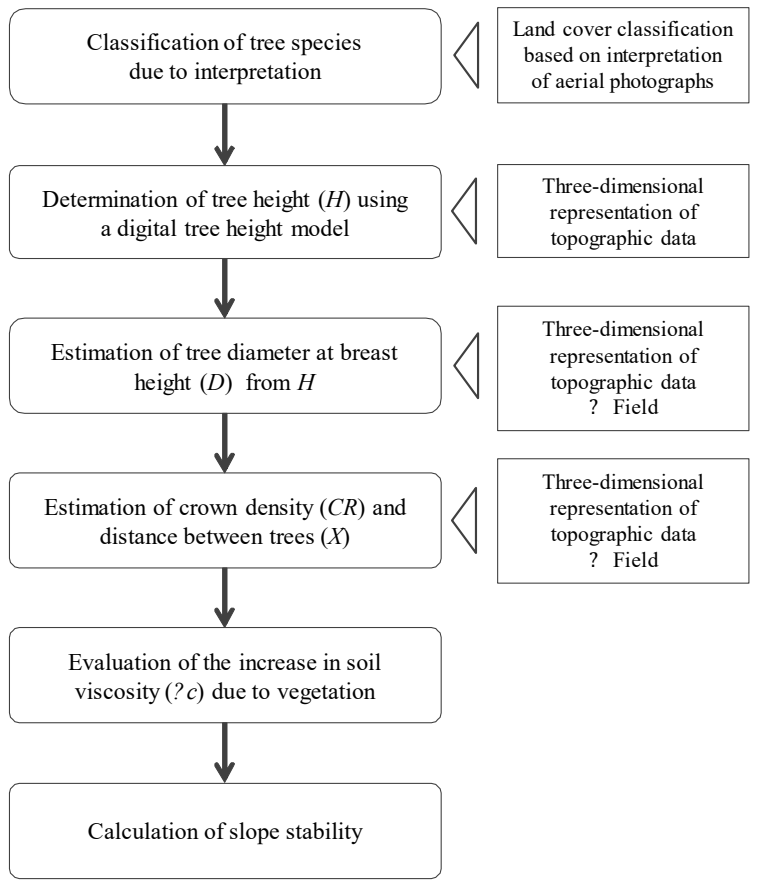

Figure 3. Flowchart of the method used to estimate changes in $\Delta c$

\subsection{Classification of tree species}

We classified the tree species in the study watershed by interpreting aerial images (Figure 4). The target watershed comprised $49 \%$ conifers (mainly Japanese cypress), 34\% broadleaf trees, and $17 \%$ bare soil due to slope failure.

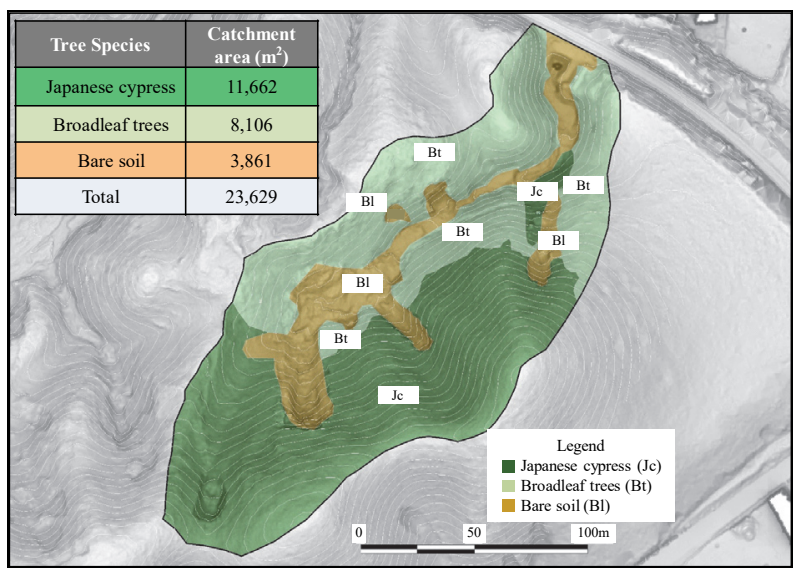

Figure 4. Land cover classification for the target watershed

\subsection{Diameter at breast height}

The average $D$ value of trees within a 10-m mesh was estimated from laser measurement data as follows. First, a digital surface model (surface height including trees) and digital elevation model (topographic model excluding trees) were determined using aerial laser measurement results. A digital tree height 
model was developed based on the differences between these models. Tree height $(H)$ was estimated from digital tree height model (Figure 5). The relational equation (Equation (4)) for $H$ and $D$ is created from that data and $D$ values obtained from field surveys in advance. $D$ values for each $10 \mathrm{~m}$ mesh could be estimated by Equation (4).

$$
D=7.5641 \mathrm{e}^{0.0784 H}(R=0.8)
$$

The distribution of $D$ values for the target watershed obtained by this method is shown in Figure 6.

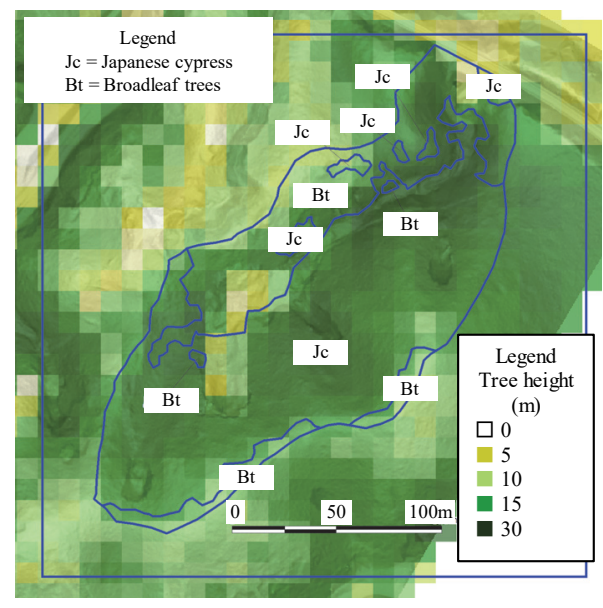

Figure 5. Tree height $(H)$ in the watershed

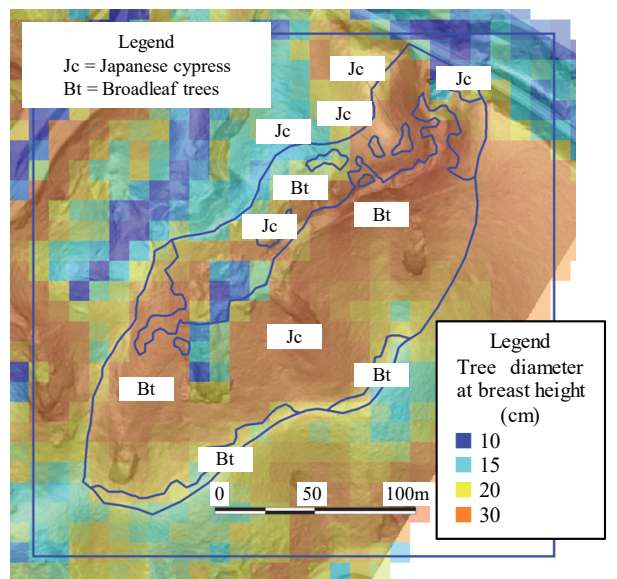

Figure 6. The diameter at breast height $(D)$ in the watershed

\subsection{Distance between trees}

A relational Equation (5) was created for the relationship between $X$ values measured at 30 locations during a survey of the study site and the crown density results $(C R) . C R$ values could be determined from aerial laser measurement data (Figure 7). For all meshes in the watershed, $X$ values were estimated using the following equation; the results are shown in Figure 8.

$$
X=C R / 23.594(R=0.5)
$$

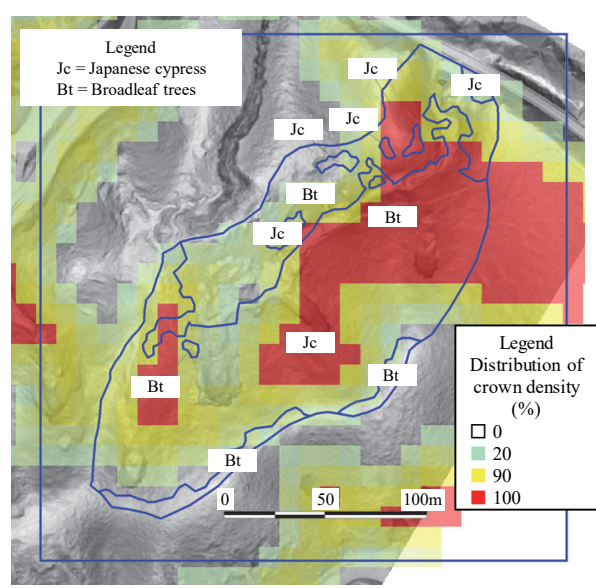

Figure 7. Distribution of crown density $(C R)$ in the watershed

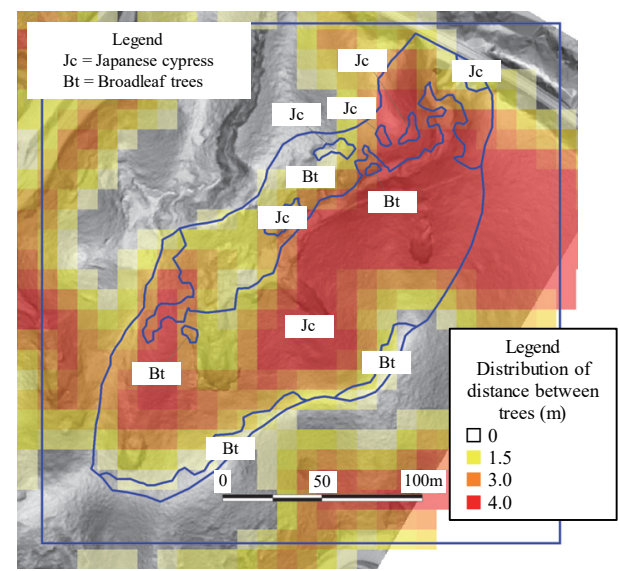

Figure 8. Distribution of distance between trees $(X)$ in the watershed

\subsection{Increase in soil viscosity due to tree root systems}

$D$ and $X$ values were calculated as described in Sections 4.1-4.3. And we determined $\Delta \mathrm{c}$ for the $10-\mathrm{m}$ mesh using Equations (2) and (3). The distribution of $\Delta \mathrm{c}$ in the watershed is shown in Figure 9.

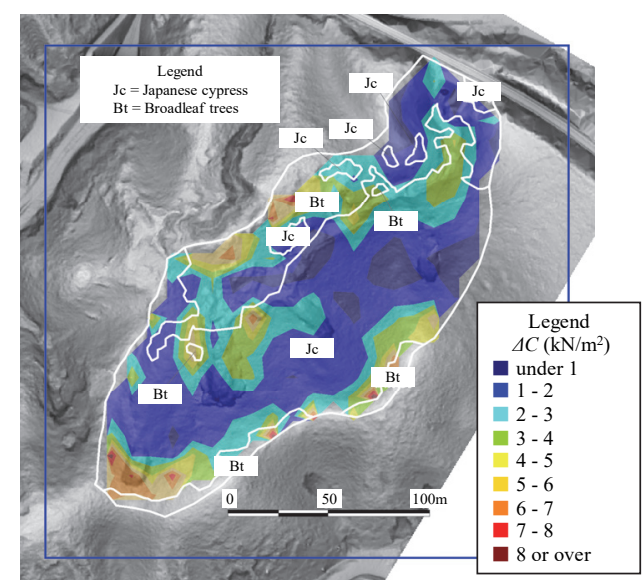

Figure 9. Distribution of changes in $\Delta c$ in the watershed 


\section{RISK ASSESSMENT CALCULATIONS BASED ON WATERSHED RAINFALL}

\subsection{Verification during the disaster}

Slope failure occurred at a number of locations within the target watershed due to heavy rains on August 16-17, 2014. We conducted a stability study based on methods that treated the heavy rainfall as an external force, using a calculation mesh of $2 \mathrm{~m} \times 2 \mathrm{~m}$, topsoil thickness values based on the proposed prediction method, and hourly rainfall data recorded near the target watershed (Figure 10). Soil strength values took $\Delta \mathrm{c}$ into account, as shown in Figure 9. We assumed that the topography of the failed portion was returned to its pre-failure state by summit-level processing methods (Fujii, 2002). Figure 11 shows the results of these calculations for a cumulative rainfall value of $380 \mathrm{~mm}$. The actual time of failure remains unclear; however, our calculations indicate that risk was higher near the failed portions. We found that the methods proposed in this study allowed successful risk assessment during rainfall.

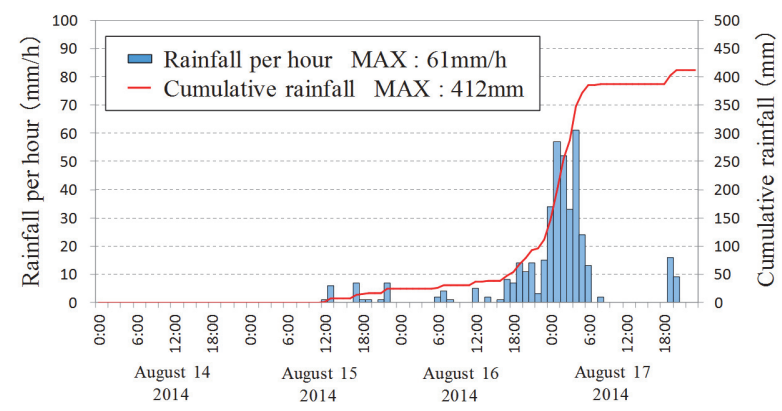

Figure 10. Rainfall history of the target watershed

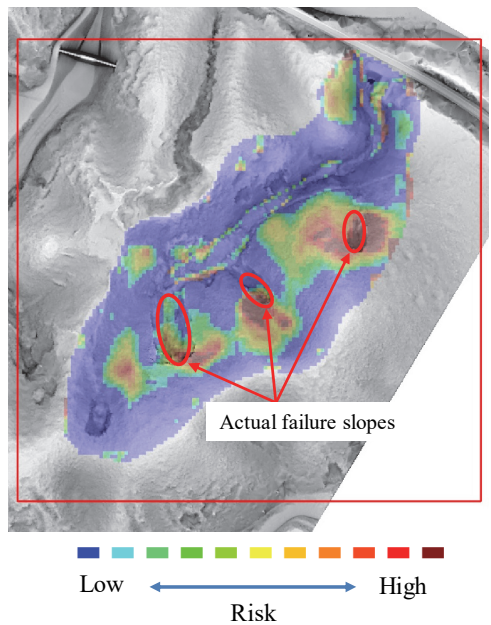

Figure 11. Slope failure risk estimated by the model, considering soil conservation by root systems

\subsection{Estimation of failure suppression due to slope vegetation}

Having shown that it was generally possible to calculate the risk of slope failure during rainfall, we next attempted to calculate the inhibition of slope failure by different types of vegetation in the watershed. We estimated a tree density of 3,000 trees/ha,

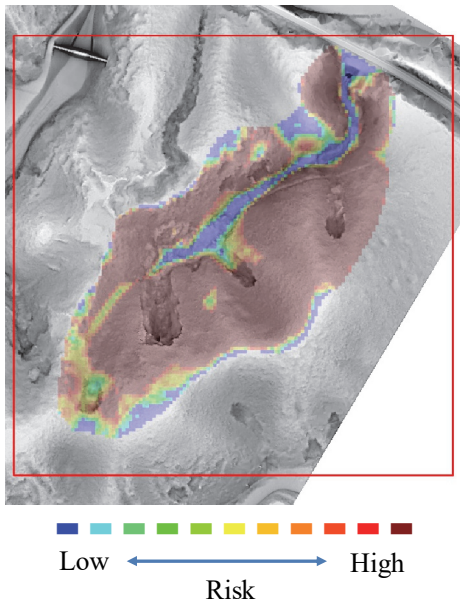

(1) Bare soil

(Each mesh is calculated with $\Delta C=0$ )

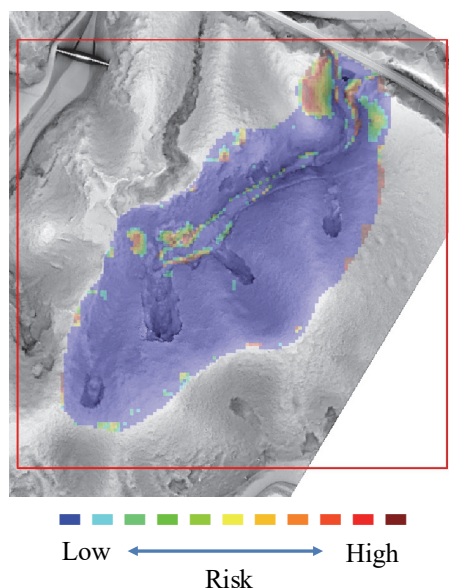

(2) Managed conifer forest with 3,000 trees/ha (no change in broadleaf trees)

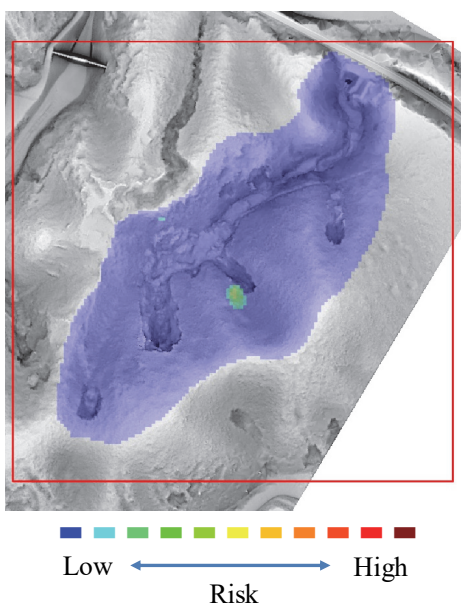

(3) Broadleaf trees distributed throughout the whole watershed (median value of $\Delta C$ for the current distribution for broadleaf trees)

Figure 12. Results of trial calculations with differing vegetation within the watershed 
assuming a forest of well-managed Japanese cypress. Using $\Delta \mathrm{c}$ as an input, we compared the results for a conifer forest to those for a broadleaf forest and for bare soil. As there is no concept of an ideal forest of broadleaf trees, the median value for broadleaf trees in the watershed was used for the increase in soil viscosity calculations. The results for a simulation using rainfall as an external force, at a cumulative rainfall of $380 \mathrm{~mm}$, are shown in Figure 12. We then compared the risk of failure given the actual vegetation in the watershed with that for vegetation consisting entirely of either managed conifers or broadleaf trees (Figure 11, Figure12(2)(3)). Compared with the risk due to actual vegetation, the risk of failure with cumulative rainfall of 380 $\mathrm{mm}$ was extremely low when the vegetation consisted entirely of managed conifers or broadleaf trees. When the watershed contained bare soil with no vegetation, i.e., with no soil conservation effect due to tree roots, there was a high risk of slope failure throughout the watershed (Figure12(1)). Thus, our calculations show that the risk of slope failure differs greatly among vegetation types, and that it is possible to assess risk based on the state of the slope vegetation along railways using rainfall as an indicator.

\section{CONCLUSION}

We presented a method for time series slope failure risk assessment using topographic data for disasters caused by heavy rains at locations near routes such as railways and roads. We also proposed methods to estimate topsoil thickness, which heavily influences slope failure risk, and the effects of trees on soil viscosity. Based on these results, we were able to approximate actual slope failures. Failure simulations based on differences in forest type are possible using these proposed methods, to evaluate risk where previous failures have occurred in the past and to identify new at-risk locations. Thus, forests may be managed based on risk assessments for intensifying heavy rains using the proposed methods.

This research focuses on how the relative spatial distribution of slope risk differs when the effect of vegetation is considered. The relative spatial distribution of slope risk is shown in plan views, and the effect of the proposed technique is indicated by showing high risk locations and differences in area. At this point, the technique is not yet capable of an assessment in terms of safety factor values, such as changes in occurrence time due to given rainfall or an evaluation of measures necessary to prevent slope failure. To achieve the said purpose, the verification of the model and improvement of precision are tasks to be solved in the future.

\section{REFERENCES}

Asano Y., Kawajiri S., Nunokawa O., Ohta N., Sugiyama T. \& Watanabe S., 2013. Proposal of the simple simulation method to estimate the stability of slope surface layer under rainfall condition (in Japanese), Japanese Geotechnical Journal, Vol.8, No.4, pp.579-595.

Atsuji M., Kitahara H. \& Ono H., 2013. Creating a secondary distribution diagram of failure deterrence in a forest stand (in Japanese), Chubu Forestry Research, No.61, pp.13-16.

Atsuji M., Kitahara H. \& Ono H., 2014. Distribution of failure deterrence by to root systems in natural broadleaf tree forests (in Japanese), Chubu Forestry Research, No.62, pp.99-102.
Fujii N., 2002. Using summit level maps to interpret topography (in Japanese), OYO Corporation, Vol.43, No.2, pp.101-109.

Nunokawa O., Ota N. \& Ishikawa S., 2013. Risk evaluation of debris flow using digital terrain model (in Japanese), Railway Technical Research Institute Report, Vol.27, No.11.

Okimura T. \& Ichikawa R., 1984. A delineation method for probable mountain slope failures by a digital land form model (in Japanese), JSCE, Vol.358/III-3, pp.69-75, June, 1985. 